\title{
Acute Pulmonary Edema Following Administration of Magnesium Sulfate in a Pregnant Patient
}

\author{
Mohammad Reza Zeraati, 1,2 (D), Taraneh Naghibi,* 1,2 [D
}

1. Dept. of Anesthesiology and Critical Care Medicine, Mousavi Hospital, Faculty of Medicine, Zanjan University of Medical Sciences, Zanjan, Iran

2. Center for Development of Clinical Research, Zanjan University of Medical Sciences, Zanjan, Iran

\begin{tabular}{|c|c|}
\hline Article Info & ABSTRACT \\
\hline doi $10.30699 / j a m b s .27 .124 .43$ & \multirow{3}{*}{$\begin{array}{l}\text { Acute pulmonary edema affects } 0.08 \% \text { to } 1.5 \% \text { of women during pregnancy and } \\
\text { during the postpartum period, and preeclampsia/eclampsia is a major obstetric cause } \\
\text { of acute pulmonary edema. We present a case of a } 23 \text {-year-old nulliparous woman } \\
\text { who was referred to tertiary medical center for preterm labor and dyspnea(Mousavi } \\
\text { Hospital). The patient complained of having suddenly developed respiratory distress } \\
\text { and a decrease in } \mathrm{O}_{2} \text { saturation following the administration of magnesium sulfate. A } \\
\text { chest radiograph taken at bedside showed widespread interstitial shadowing } \\
\text { consistent with pulmonary edema. The patient was given prompt treatment, and she } \\
\text { achieved full recovery. Pharmacological agents are one of the defendants used for } \\
\text { lung edema during pregnancy. It is important to pay attention to lung edema due to } \\
\text { tocolytic administration. }\end{array}$} \\
\hline $\begin{array}{c}\text { Received: 2019/01/15; } \\
\text { Accepted: 2019/04/10; } \\
\text { Published Online: } 10 \text { Jul 2019; }\end{array}$ & \\
\hline $\begin{array}{l}\text { Use your device to scan and read the } \\
\text { article online }\end{array}$ & \\
\hline
\end{tabular}

Keywords: Magnesium sulfate, Pulmonary edema, Tocolytic, Pregnancy

Corresponding Information:

Dept. of Anesthesiology and Critical Care Medicine, Mousavi Hospital, Faculty of Medicine, Zanjan

University of Medical Sciences, Zanjan, Iran E-mail: tnaghibi@zums.ac.ir

\section{Introduction}

The accumulation of fluid in the pulmonary interstitial spaces is the pathophysiology of pulmonary edema. Physiological changes can predispose pregnant women to this complication (1). Being an uncommon event, the risk of pulmonary edema is around $0.08 \%$ to $1.5 \%$ in women during pregnancy and in the postpartum period (2). Maternal and fetal morbidity and mortality increase in this situation (3). Various etiologies can result in pulmonary edema in pregnant patients, including preeclampsia, tocolytics, sepsis, pre-existing cardiac disease, and pregnancy-associated cardiac disease, fluid overload, and multiple gestations $(2,4)$. The infusion of fluids in women who submitted to induced labor, caesarean sections, and prophylaxis with magnesium sulfate are known causes of pulmonary edema (5). Few cases of acute pulmonary edema resulting from the administration of magnesium sulfate have been reported to date. The diagnosis and treatment of this complication are vital. Here, we describe a case of acute pulmonary edema that was likely caused by the administration of magnesium in a pregnant woman.

\section{Case Report}

A nulliparous 23-year-old woman was referred to tertiary medical center for preterm labor and dyspnea (Mousavi Hospital). She had no past medical history. The patient complained of having suddenly developed respiratory distress and a decrease in $\mathrm{O}_{2}$ saturation following administration of magnesium sulfate. She was transferred to our third level intensive care unit (ICU).

On arrival to ICU, her blood pressure was $120 / 75$ along with a respiratory rate of 50 breath per minute and Spo 2=90\%; hence, $20 \mathrm{mg}$ of furosemide was injected and the patient was intubated because of the respiratory distress. All necessary evaluations were performed for the patient including chest radiography (Figure 1), CT angiography (Figure 2), echocardiography, a complete workup for autoimmune disease, and sepsis. A chest radiograph taken at bedside revealed widespread interstitial shadowing consistent with pulmonary edema (Figure 1). There was no evidence of the thromboembolic event in the CT angiography report. On echocardiography, the cardiac function was normal, and there was no sign of valvular 
heart disease or wall motion abnormality. Laboratory findings were as follows: 


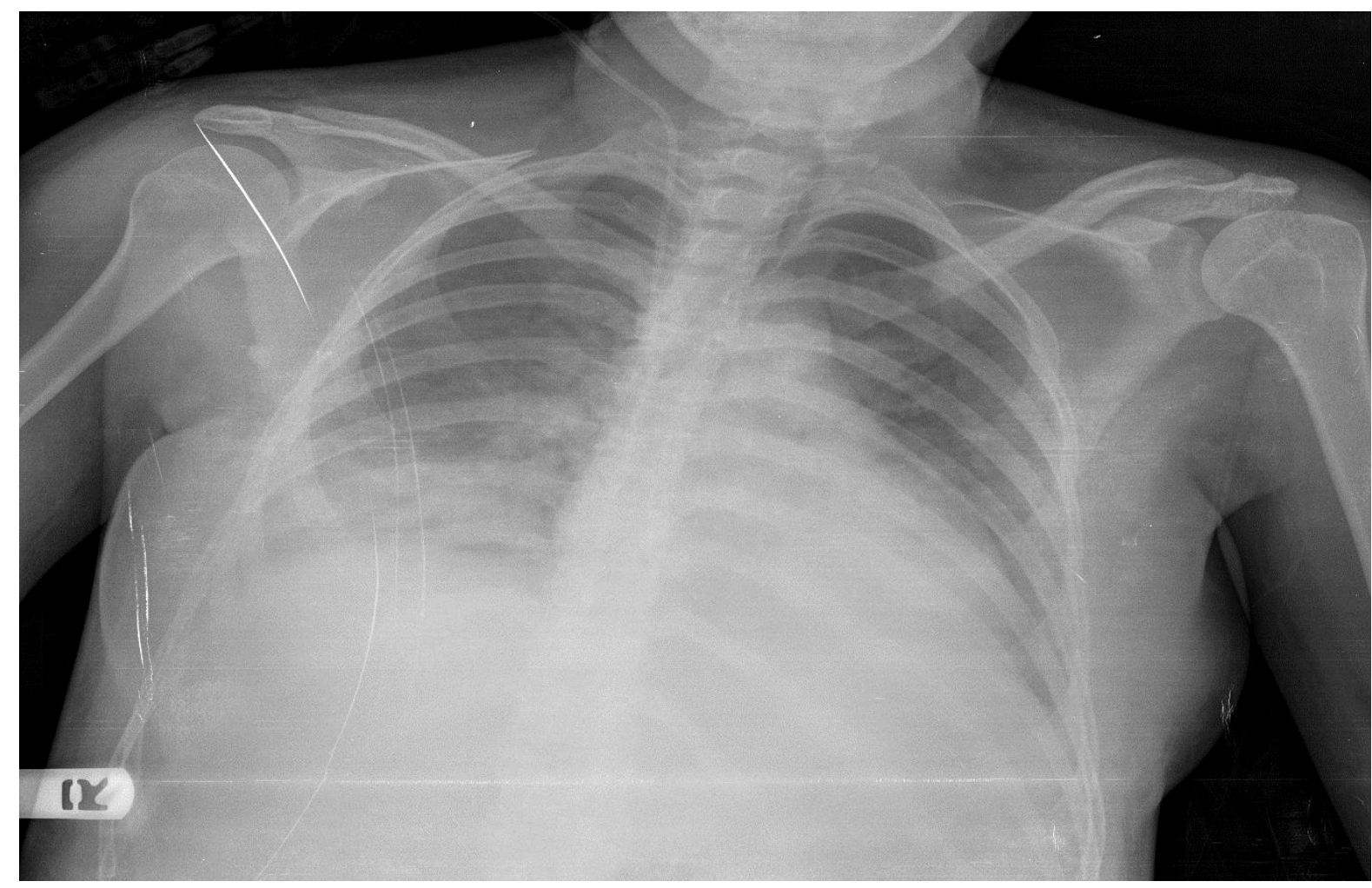

Figure 1. Chest x-ray

Bedside chest radiographs shows evidence of both interstitial and alveolar edema. Alveolar edema manifests as nodular opacities.

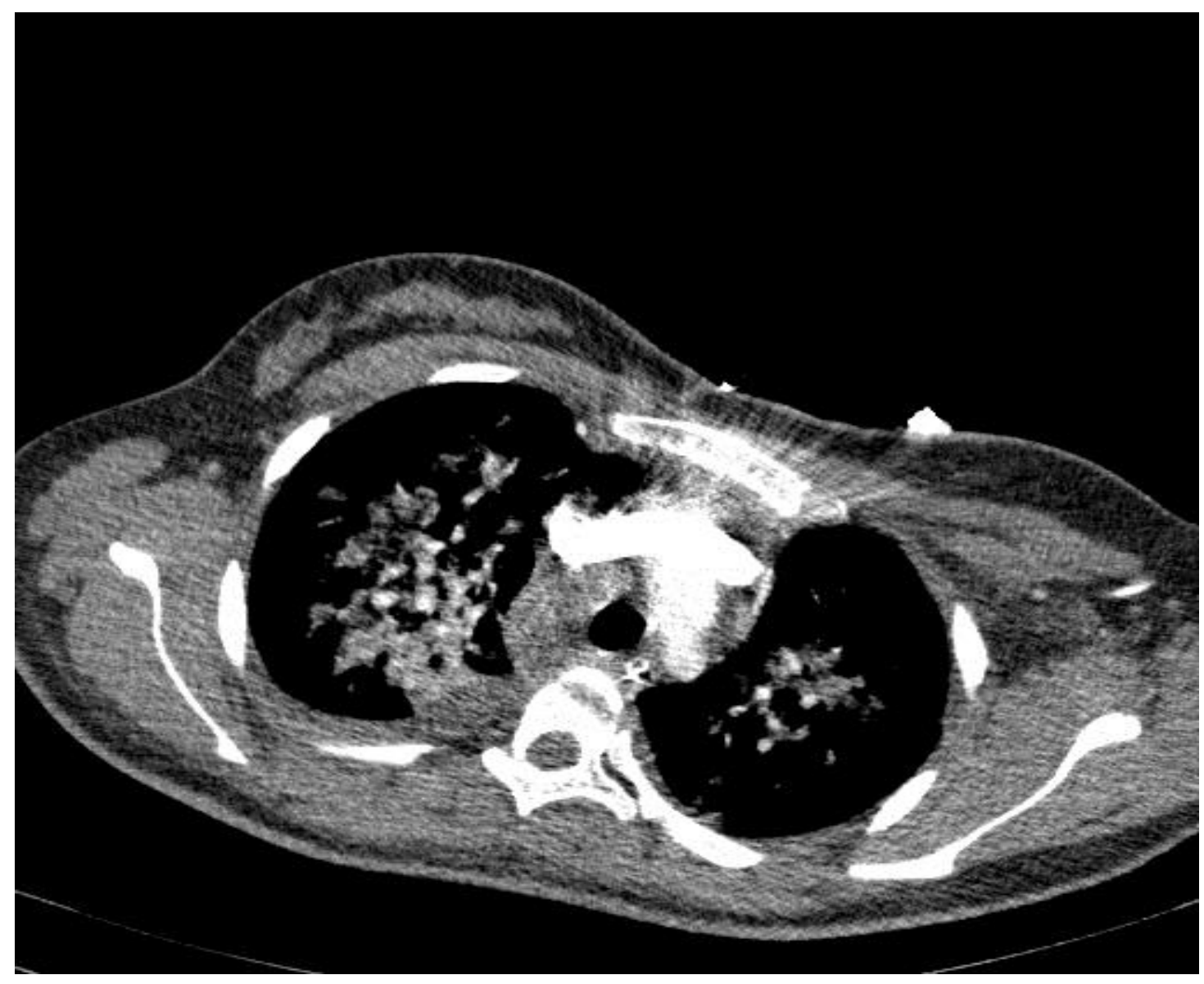

Figure 2. CT Pulmonary Angiogram

Ground-glass opacity and centrilobular nodules are observed in the CT angiogram. 
Anti ds DNA=0.2 IU/Ml

$\mathrm{Hb}=11.4 \mathrm{~g} / \mathrm{dl} \quad$ Lymph=6.4 Bil total $=0.7 \mathrm{mg} / \mathrm{dl}$
FANA=negative
$\mathrm{HCT}=34.7 \% \quad$ ALT $=20 \mathrm{U} / \mathrm{L}$

Bil direct $=0.5 \mathrm{mg} / \mathrm{dl}$

$\mathrm{Plt}=167 /$ microlier

$\mathrm{AST}=22 \mathrm{U} / \mathrm{L}$

Procalcitonin $<0.2 \mathrm{ng} / \mathrm{mL}$

ABG, before intubation, showed moderate respiratory alkalosis $(\mathrm{pH}=7.48, \mathrm{Paco} 2=32, \mathrm{HCO} 3=22$ $\mathrm{O}_{2}$ sat $=89 \%$ )

The medical team concluded to perform a Cesarean section to improve respiratory conditions. After 24 hours of admission, Caesarean section was performed, and the mechanical ventilation of the patient was resumed. Airway resistance under mechanical ventilation was about 10 to $15 \mathrm{~cm} \mathrm{H}_{2} \mathrm{O}$ and static compliance was about $33 \mathrm{~cm} \mathrm{H}_{2} \mathrm{O}$. We performed an open lung maneuver with airway pressure release ventilation mode (A.P.R.V) for 24 hours. Intravenous furosemide (bolus $40 \mathrm{mg}$ over $2 \mathrm{~min}$ ) was employed, and repeated after $30 \mathrm{~min}$, and its infusion was continued for 24 hours. A chest X-radiography was carried out the following day revealing a normal lung activity. We successfully extubated the patient after 48 hours of Cesarean section. The patient's condition improved, and she was discharged one week after ICU admission.

\section{Discussion}

One of the most common causes of morbidity and mortality during pregnancy is acute pulmonary edema $(6,7)$. In 2011, Cantwell reported that it is the fourth most common form of maternal morbidity (6). There is little information about the natural history of pulmonary edema among pregnant women (1). Fluid redistribution may be caused by sympathetic activation in the stress status which could lead to pulmonary edema (8). Due to the decreased plasma protein osmotic pressure, even small changes in hydrostatic pressure may cause pulmonary edema during pregnancy (9).

Various causes for pulmonary edema can be suggested for this case study, including aspiration, sepsis, cardiac disease, preeclampsia, and pharmacological drugs.

There was no evidence for fluid overload or valvular heart disease in echocardiography. CT Angiography did not detect any evidence for aspiration. According to primary hospital records and our evaluations, there was no evidence of fluid overload or other important causes for pulmonary edema in this patient and pulmonary edema has occurred after the administration of magnesium sulfate. Pharmacological agents are one of the defendants for lung edema during pregnancy. $\beta$ adrenergic tocolytic agents, corticosteroids, magnesium sulfate and illicit drugs including cocaine are the most common drugs that cause pulmonary edema during the pregnancy (9).

ARDS is rare $(0.5 \%-5 \%)$ but is a feared complication of tocolysis with beta-2-mimetic agents and magnesium sulfate and the lesions of alveolar capillary membrane prominent (10). Magnesium sulfate is one of the most commonly used tocolytics for preterm labor (11). Samol et al. demonstrated that MgSO4 is associated with the development of pulmonary edema (12) and it is one of the morbid complications of this tocolytic. In the case of the present patient, her respiratory complications began at the time of the administration of magnesium sulfate.

The recommended treatment for pulmonary edema is airway management, oxygen administration, the application of open lung maneuver and administration of furosemide.

Fortunately, her symptoms were alleviated after 24 hours by application of open lung maneuver and diuretic administration.

\section{Conclusion}

Pharmacological agents are one of the defendants for lung edema during pregnancy. This complication occurred in the present woman with the administration of magnesium sulfate to control her preterm labor. When respiratory symptoms such as hypoxemia, tachypnea, and dyspnea occur after administration of magnesium sulfate, it is important to pay attention to lung edema due to tocolytic administration.

\section{Acknowledgment}

This research did not receive any specific grant from funding agencies.

\section{Conflict of Interest}

Authors declared no conflict of interests.

\section{References}

1. Lee JY, Kwon HJ, Park SW, et al. Acute pulmonary edema caused by takotsubo cardiomyopathy in a pregnant woman undergoing transvaginal cervical cerclage: A case report. Medicine (Baltimore). 2017; 96(1): e5536 [DOI:10.1097/MD.0000000000005536]

2. Sciscione AC1, Ivester T, Largoza M, et al. Acute pulmonary edema in pregnancy. Obstet Gynecol. 2003; 101:511-5. [DOI:10.1097/00006250-200303000-00016] 
3. Karamchandani K. Bortz B, Vaida S. Acute pulmonary edema in pregnancy. Am J Case Rep. 2016; 17: 682-85. [DOI:10.12659/AJCR.898937]

4. Yeast JD, Halberstadt G, Meyer BA, et al. The risk of pulmonary edema and colloid osmotic pressure changes during magnesium sulfate infusion. Am J Obstet Gynecol. 1993; 169(6):1566-71. [DOI:10.1016/00029378(93)90438-O]

5. Cantwell R, Clutton Brock T, Cooper G, et al. Saving mothers' lives: reviewing maternal deaths to make motherhood safer: 2006-2008. The eighth report of the confidential enquiries into maternal deaths in the United Kingdom. BJOG. 2011;118 Suppl 1:1-203. [DOI:10.1111/j.1471-0528.2010.02847.x]

6. Cypher RL. Pulmonary edema in obstetrics: essential facts for critical care nurses. AACN Adv Crit Care. 2018; 29(3):327-35. [DOI:10.4037/aacnacc2018958]

7. Hsieh YT, Lee TY, Kao JS, et al. Treating acute hypertensive cardiogenic pulmonary edema with high- dose nitroglycerin. Turk J Emerg Med. 2018; 18(1):3436. [DOI:10.1016/j.tjem.2018.01.004]

8. MG Z. Pulmonary edema: etiology and treatment. Semin Perinatol. 1997; 21:298-306. [DOI:10.1016/S01460005(97)80072-9]

9. River G,Nicole A, Stucki D ,et al. Lesional pulmonary edema with tocolysis by hexoprenaline sulfate. Schweitz Med Wochenschr.1992; 122(7):237-41.

10. Kim MK, Lee SM, Oh JW, et al. Efficacy and side effect of ritodrine and magnesium sulfate in threatened preterm labor. Obstet Gynecol Sci. 2018; 61(1):63-70. [DOI:10.5468/ogs.2018.61.1.63]

11. Dennis A, Solnordal CB. Acute pulmonary oedema in pregnant women. Anaesthesia. 2012; 67(6):646-59. [DOI:10.1111/j.1365-2044.2012.07055.x]

12. Samol JM, Lambers DS. Magnesium sulfate tocolysis and pulmonary edema: the drug or the vehicle? Am J Obstet Gynecol. 2005;192(5):1430-2. [DOI:10.1016/j.ajog.2005.02.093]

\section{How to Cite This Article:}

Zeraati M R, Naghibi T. Acute Pulmonary Edema Following Administration of Magnesium Sulfate in a Pregnant Patient. J Adv Med Biomed Res. 2019; 27 (124):43-46

\section{Download citation:

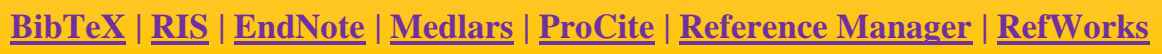

\section{Send citation to:}
$\$$ Mendeley
2 Zotero
; RefWorks RefWorks 